\title{
Noise-Source Separation Using Internal and Far-Field Sensors for a Full-Scale Turbofan Engine
}

Lennart S. Hultgren and Jeffrey H. Miles

Glenn Research Center, Cleveland, Ohio 


\section{NASA STI Program . . . in Profile}

Since its founding, NASA has been dedicated to the advancement of aeronautics and space science. The NASA Scientific and Technical Information (STI) program plays a key part in helping NASA maintain this important role.

The NASA STI Program operates under the auspices of the Agency Chief Information Officer. It collects, organizes, provides for archiving, and disseminates NASA's STI. The NASA STI program provides access to the NASA Aeronautics and Space Database and its public interface, the NASA Technical Reports Server, thus providing one of the largest collections of aeronautical and space science STI in the world. Results are published in both non-NASA channels and by NASA in the NASA STI Report Series, which includes the following report types:

- TECHNICAL PUBLICATION. Reports of completed research or a major significant phase of research that present the results of NASA programs and include extensive data or theoretical analysis. Includes compilations of significant scientific and technical data and information deemed to be of continuing reference value. NASA counterpart of peer-reviewed formal professional papers but has less stringent limitations on manuscript length and extent of graphic presentations.

- TECHNICAL MEMORANDUM. Scientific and technical findings that are preliminary or of specialized interest, e.g., quick release reports, working papers, and bibliographies that contain minimal annotation. Does not contain extensive analysis.

- CONTRACTOR REPORT. Scientific and technical findings by NASA-sponsored contractors and grantees.
- CONFERENCE PUBLICATION. Collected papers from scientific and technical conferences, symposia, seminars, or other meetings sponsored or cosponsored by NASA.

- SPECIAL PUBLICATION. Scientific, technical, or historical information from NASA programs, projects, and missions, often concerned with subjects having substantial public interest.

- TECHNICAL TRANSLATION. Englishlanguage translations of foreign scientific and technical material pertinent to NASA's mission.

Specialized services also include creating custom thesauri, building customized databases, organizing and publishing research results.

For more information about the NASA STI program, see the following:

- Access the NASA STI program home page at http://www.sti.nasa.gov

- E-mail your question via the Internet to help@ sti.nasa.gov

- Fax your question to the NASA STI Help Desk at $443-757-5803$

- Telephone the NASA STI Help Desk at 443-757-5802

- Write to: NASA Center for AeroSpace Information (CASI) 7115 Standard Drive Hanover, MD 21076-1320 
NASA/TM-2009-215834

AIAA-2009-3220

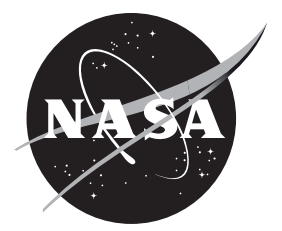

\section{Noise-Source Separation Using Internal and Far-Field Sensors for a Full-Scale Turbofan Engine}

Lennart S. Hultgren and Jeffrey H. Miles

Glenn Research Center, Cleveland, Ohio

Prepared for the

15th Aeroacoustics Conference (30th AIAA Aeroacoustics Conference) cosponsored by AIAA and CEAS

Miami, Florida, May 11-13, 2009

National Aeronautics and

Space Administration

Glenn Research Center

Cleveland, Ohio 44135 


\section{Acknowledgments}

This work was supported by the NASA Fundamental Aeronautics Program Subsonic Fixed Wing Project. The NASA Fundamental Aeronautics Program has the principal objective of overcoming today's national challenges in air transportation. The work herein is part of a NASA-internal and NASA-sponsored external research effort aimed at the development of component-based aircraft noise-prediction capability and tools. The reduction of aircraft noise is critical for enabling the anticipated large increase in future air traffic.

This work was sponsored by the Fundamental Aeronautics Program at the NASA Glenn Research Center.

Level of Review: This material has been technically reviewed by technical management.

Available from

NASA Center for Aerospace Information 7115 Standard Drive

Hanover, MD 21076-1320
National Technical Information Service 5285 Port Royal Road Springfield, VA 22161 


\title{
Noise-Source Separation Using Internal and Far-Field Sensors for a Full-Scale Turbofan Engine
}

\author{
Lennart S. Hultgren and Jeffrey H. Miles \\ National Aeronautics and Space Administration \\ Glenn Research Center \\ Cleveland, Ohio 44135
}

\begin{abstract}
Noise-source separation techniques for the extraction of the sub-dominant combustion noise from the total noise signatures obtained in static-engine tests are described. Three methods are applied to data from a static, full-scale engine test. Both 1/3-octave and narrow-band results are discussed. The results are used to assess the combustion-noise prediction capability of the Aircraft Noise Prediction Program (ANOPP). A new additional phase-angle-based discriminator for the three-signal method is also introduced.
\end{abstract}

\section{Introduction}

Noise generated in the jet engine core, by sources such as the compressor, combustor, and turbine, can be a significant contribution to the overall noise signature at low-power conditions, typical of approach flight. At high engine power during takeoff, jet and fan noise have traditionally dominated over core noise. However, current design trends and expected technological advances in engine-cycle design as well as noise-reduction methods are likely to reduce non-core noise even at engine-power points higher than approach. The result of such changes will be to elevate the importance of turbomachinery core noise. Also, future airport regulations may force further noise reduction at the approach flight conditions, thus emphasizing the need for reductions in core noise.

Ref. 1 and Ref. 2, in the collection by Ref. 3, summarize the status and understanding of turbomachinery contributions to flight vehicle noise at the beginning of the 1990's. Whereas jet and fan noise research and understanding have progressed; the state of the art in core-noise prediction has not been equally advanced. Low frequency core noise up to about $1 \mathrm{kHz}$, particularly in aft quadrants, is generally attributed to combustion noise. Turbine broadband and discrete-tone noise normally falls in the frequency range of several $\mathrm{kHz}$ and above. The discrete tones are caused by stator/rotor wakes interacting with downstream rotors/stators and potential fields interacting with upstream and downstream blade rows. Internal turbine broadband noise is caused by rotor/stator lift fluctuations due to flow turbulence. However, there is also a significant broadband component in the far field associated with scattering of the discrete turbine tones by the jet shear layer(s). This so called hay-stacking effect usually dominates the broadband noise generated within the turbine. Compressor noise occurs mainly in the forward direction as discrete tones at the first stage blade-passing frequency $(\mathrm{kHz})$ or as a compressor-disk tone at the compressor shaft frequency (several hundred $\mathrm{Hz}$ ). The compressor is commonly not considered a significant noise source for today's high-bypass turbofan engines. The present paper is concerned with the combustion noise component of the core noise.

Combustion noise is either of the direct or indirect type. The unsteady combustion process is the source of pressure, entropy, and vorticity fluctuations. The frequency scale is set by the unsteady combustion process and falls in the range of 400-500 $\mathrm{Hz}$. A fraction of the pressure disturbances are acoustic pressure fluctuations with the balance being hydrodynamical unsteadiness. The former is what is referred to as direct combustion noise. Its spectrum is modified by the combustor geometry as well as pressure feedback on the unsteady combustion process itself. The direct combustion noise is reduced due to transmission effects during its propagation through the turbine stages. The combustor entropy (temperature) fluctuations are convected downstream with the local mean velocity and get converted to acoustic pressure fluctuations in the turbine and other regions of rapid flow change. This is the indirect process of 
turbomachinery combustion noise generation. This is potentially a very effective mechanism and occurs at all turbine stages. The indirect noise occurs in the same basic frequency range as the direct one, but their spectral-distribution shapes could be quite different. The relative importance of direct and indirect combustion noise is still an unresolved issue. Any quasi-steady temperature streak ingested by the turbine would have an effect similar to a fan/compressor inlet disturbance/vortex and would generate noise in the blade-passing frequency range. This possibility should be classified as a turbine self-generated noise mechanism.

The direct measurement of turbofan-engine combustion noise is difficult because of the presence of jet noise in the frequency range of interest. Since in-flight effects reduce jet noise more than combustion noise, combustion noise can be a significant contributor to aircraft approach noise but masked by jet noise under the corresponding static-engine test condition. To overcome this obstacle, researchers ${ }^{4-13}$ developed coherence techniques utilizing engine-internal as well as far-field measurements to identify the far-field combustion noise component. Modal analyses ${ }^{14-17}$ were also carried out to determine the source and propagation characteristics of combustion noise.

In this paper, a discussion of noise-source separation techniques for application to engine test-stand data and an assessment of a current prediction method applied to a static-engine test will be presented.

\section{Coherence Techniques}

Figure 1 illustrates a typical three-sensor arrangement for a measurement utilizing correlation/coherence techniques to determine the combustion-noise component of the far-field noise signature. Measurement station ' $\mathrm{C}$ ' is

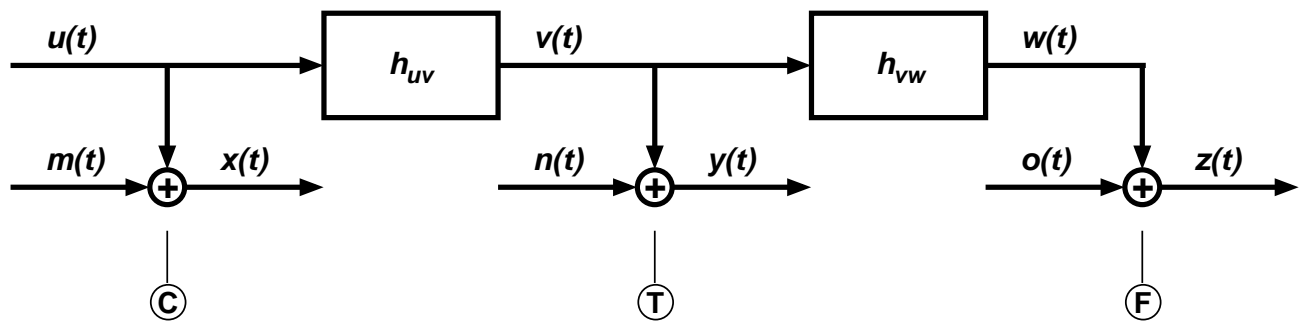

Figure 1. Schematic Diagram for Coherence-Technique Measurements

located inside the combustor, station ' $\mathrm{T}$ ', if present, is typically located in the core tail pipe, and station ' $\mathrm{F}$ ' is located in the far field. The signals $u(t), v(t)$, and $w(t)$ represent the acoustic combustion-noise signal at the three stations as functions of time $t$. These 'desired' signals cannot be directly obtained by themselves because of the presence of the random uncorrelated 'noise' signals $m(t), n(t)$, and $o(t)$ at the different stations. However, the downstream signals $v(t)$ and $w(t)$ are uniquely determined by the impulse-response functions $h_{u v}$ and $h_{v w}$ and the previous-station signals $u(t)$ and $v(t)$, respectively. The measurable signal, $x(t), y(t)$, or $z(t)$, at each station is the sum of the 'desired' and corresponding 'noise' signals. The signals $m(t), n(t)$, and $o(t)$ can be taken as mutually uncorrelated as well as uncorrelated with the combustion-noise signal $u(t), v(t)$, or $w(t)$ at all the stations. The signal $m(t)$ is to a large extent caused by hydrodynamical pressure fluctuations (pseudo sound) in the combustor and possibly also higher acoustic modes present in the combustor but cut-off in the downstream tail pipe and can potentially be quite large. The signals $n(t)$ and $o(t)$ are mainly due to acoustic pressure fluctuations from other noise sources and particularly $o(t)$ can be dominant in the frequency range of interest due to the presence of jet noise. The goal is to determine the one-sided auto-spectrum $G_{w w}(f)$, with $f$ denoting frequency, i.e., the combustion-noise component of the total far-field noise signature $G_{z z}(f)$. The diagnostic technique is commonly referred to as the coherent-output-power method when only one sensor inside the engine is utilized in combination with the far field microphone and will be discussed next. Then the three-signal technique will be addressed.

\section{A. Coherent-Output-Power Method}

Ref. 4 describes the basic formulation for the coherent-output-power method. If the sensor inside the combustor and one in the far field (Fig. 1) are used in this technique, it follows that the coherent combustion-noise spectrum is given by

$$
G_{w w}(f)=\frac{\left|G_{u w}(f)\right|^{2}}{G_{u u}(f)}=\frac{\left|G_{x z}(f)\right|^{2}}{G_{u u}(f)}=\frac{\left|G_{x z}(f)\right|^{2}}{G_{x x}(f)-G_{m m}(f)} \approx \frac{\left|G_{x z}(f)\right|^{2}}{G_{x x}(f)}=\gamma_{x z}^{2}(f) G_{z z}(f)
$$




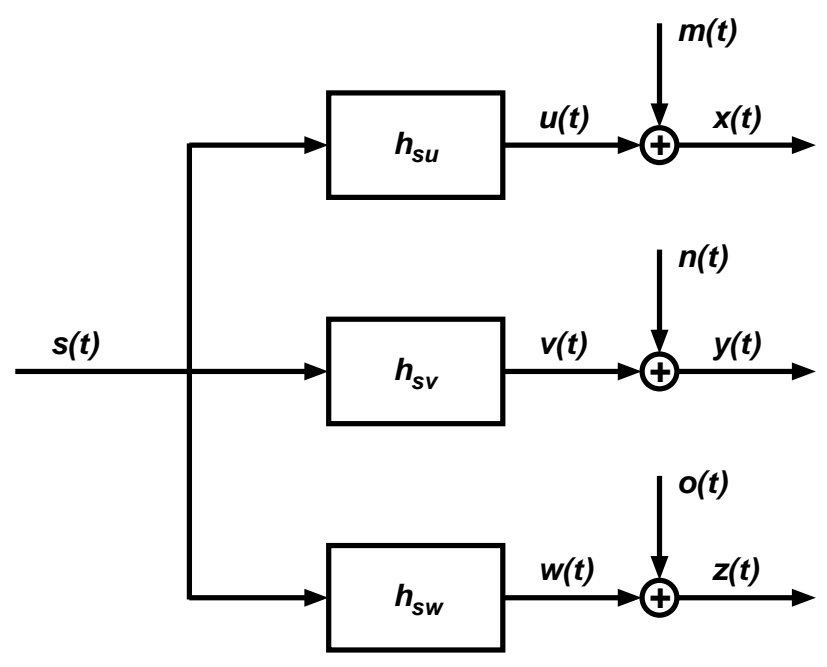

Figure 2. General Schematic Diagram for Three-Signal-Technique

regardless of the output noise $G_{o o}(f) . G_{\alpha \alpha}, G_{\alpha \beta}, \gamma_{\alpha \beta}=\left|G_{\alpha \beta}\right| / \sqrt{G_{\alpha \alpha} G_{\beta \beta}}$ denote the one-sided auto-spectrum, cross-spectrum and coherence of the signals $\alpha$ and $\beta$, where $\alpha$ and $\beta$ are dummy indexes. Note that the measured $G_{x x}$ is a positive-biased estimate for the unknown input spectra $G_{u u}$ and, consequently, the second-to-last step in Eq. (11) is only a valid approximation when the unknown $G_{m m}$ can be assumed to be small compared to $G_{x x}$. In view of the certain presence of nonpropagating pressure fluctuations in the combustor, i.e., $G_{m m} \neq 0$, Eq. 11 is quite likely to underpredict the actual coherent output spectrum. Furthermore, the spectra are estimated using a finite observation time and, consequently, the signal $z(t)$ needs to be time shifted to account for a propagation-time delay in the computation of the cross-spectrum $G_{x z}$ in order to yield a meaningful result.

Karchmer and colleagues ${ }^{5-8}$ showed successful application of coherence techniques to measurements obtained using a static AVCO-Lycoming YF102 turbofan engine instrumented with internal as well as far-field microphones. A typical result showed the combustion coherent output power in the 120 degree direction (aft quadrant) to roughly have a dome-shaped spectral distribution in the range 0 to $200 \mathrm{~Hz}$ with the peak at about $125 \mathrm{~Hz}$. At 43 percent engine speed, the peak was about $6 \mathrm{~dB}$ lower than the peak of the total far-field spectrum located at $120 \mathrm{~Hz}$. The dome edges were about $20 \mathrm{~dB}$ lower at $40 \mathrm{~Hz}$ and $200 \mathrm{~Hz}$. Similar coherence-function results also were obtained from static tests of Pratt \& Whitney JT15D ${ }^{9}$ and General Electric CF6-50 ${ }^{10}$ engines.

\section{B. Three-Signal-Coherence Method}

Chung $^{18}$ developed a three-signal coherence technique for microphone flow-noise rejection. Figure 2 shows the general block diagram for this method, where $s(t)$ is the source signal and, as before, $u(t), v(t)$, and $w(t)$ are the coherent signals, $m(t), n(t)$, and $o(t)$ represent mutually uncorrelated noise, and $x(t), y(t)$, and $z(t)$ are the measurable signals. The coherent auto-spectra at the three measuring stations in Fig. 2 are given by

$$
\begin{aligned}
G_{u u}(f) & =\frac{\left|G_{x y}(f)\right|\left|G_{x z}(f)\right|}{\left|G_{y z}(f)\right|}, \\
G_{v v}(f) & =\frac{\left|G_{x y}(f)\right|\left|G_{y z}(f)\right|}{\left|G_{x z}(f)\right|}, \\
G_{w w}(f) & =\frac{\left|G_{x z}(f)\right|\left|G_{y z}(f)\right|}{\left|G_{x y}(f)\right|} .
\end{aligned}
$$

However, the three-signal method also applies to the situation shown in Fig. 1 where the measuring stations and, consequently, the signals $u(t), v(t)$, and $w(t)$ are 'sequential' rather than 'parallel-output' measurements as in Fig. 2 Krejsa $^{11}$ considered the situation depicted in Fig. 1 and obtained Eq. $2 C$ as his far-field result. The three-signal coherence technique used by Krejsa ${ }^{11-13}$ eliminates the bias error in the coherent combustion-noise measurements due to engine-internal nonpropagating pressure fluctuations.

The strength of the three-signal method is that it involves only measured cross-spectra. The measured crossspectra are affected by extraneous noise only if this noise correlates between measurement locations. This can often 
be avoided by an appropriate spatial separation of the sensors involved and the three-signal method then provides unbiased estimates of the coherent auto-spectra. In contrast, measured auto-spectra will always include a positive definite contribution from the extraneous noise.

Krejsa compared results obtained using the earlier coherent-output-power and the new three-signal methods for YF102, ${ }^{11-13}$ JT15D, ${ }^{12}$ and CF6-50 ${ }^{12}$ static-engine tests. ${ }^{8-10}$ He found that the older method consistently underpredicted the combustion noise spectra by several $\mathrm{dB}$ at low engine speeds and of the order of $10 \mathrm{~dB}$ at a high engine speed. Ref. 13 also discussed two other techniques ${ }^{19,20}$ for isolating the combustion noise using only far-field measurements, one of which introduced a model for the jet noise. ${ }^{20}$ The three-signal coherence technique also was used by Shivashankara ${ }^{21}$ to study core noise in a Pratt \& Whitney JT9D engine.

The three-signal coherence data for the YF102, JT15D, and CF6-50 static-engine tests were further examined and correlated by von Glahn and Krejsa. ${ }^{22}$ The suggested correlations utilized one, two, and four spectral segments to capture perceived peaks in the far-field core-noise spectra. Generally, the sound pressure levels at the singlesegment spectrum peak, the higher-frequency two-segment spectrum peak, and the two higher-frequency four-segment spectrum peaks scaled with a heat-release parameter as in the semi-empirical model used in ANOPP, ${ }^{23,24}$ whereas the low-frequency segments scaled with the combustor exit velocity to the fourth power. They stated that the four-segment spectra provided the best overall fit to the data, but also that the two-segment spectrum appeared to be a reasonable representation of the combustion noise. However, the data comparisons do not generally show the expected $3 \mathrm{~dB}$ increase at the intersection of the multi-segment spectra, which renders their conclusions less clear. Nevertheless, their results show that the assumption of a single-peaked far-field combustion-noise spectrum with the peak fixed at 400 $\mathrm{Hz}$, as used in ANOPP, can be questioned.

It is also possible to separate core noise from jet noise using three far-field microphones since each would pick up correlated core noise and uncorrelated external noise from the jet. ${ }^{21,25}$ As long as the spatial (polar angle) separation of the microphones is large enough, the jet noise at each location can be assumed to be mutually uncorrelated and Eq. (2) would apply. Ref. 25 analyzed data from a Honeywell TECH977 static test ${ }^{26}$ using a three-signal far-field method, among other multiple-microphone signal-processing techniques. ${ }^{27}$ They found that the method worked well in frequency regions where a single engine-internal source was dominant. The method did not perform well for frequencies where multiple self-correlated internal noise sources were of comparable magnitude, e.g. in the relatively limited frequency range where combustion noise and turbine-broadband noise overlapped.

\section{Results}

\section{A. Static-Engine Test Data}

Data obtained during the NASA/Honeywell EVNERT ${ }^{26}$ program is used to assess the combustion-noise prediction capability of ANOPP. The engine-internal instrumentation in EVNERT configuration 35 included high-temperature pressure sensors with air cooling in a combustor ingnitor port (CIP1) and at the turbine exit (T551 and T552). Pressure time histories at the internal sensors CIP1 and T551 and the aft-quadrant far-field microphone located in the $130^{\circ}$ polar direction (measured from the inlet) are used herein. The EVNERT data acquisition system had a sampling rate of $65,536 \mathrm{~Hz}$ and a duration of about $70 \mathrm{~s}$, leading to time histories with just over 4.5 million data points. Each time series is here analyzed using an FFT length of 8192 points (corresponding to an $8 \mathrm{~Hz}$ frequency resolution or bin width), Hanning windowing, and a 50 percent data-segment overlap. The narrow-band auto spectra, resulting from $M=1117$ averages, are then summed up to yield the corresponding 1/3-octave SPL. The 1/3-octave far-field total SPL results are in full agreement with the Honeywell provided 1/3-octave SPL data.

\section{B. Source-Separation Implementation}

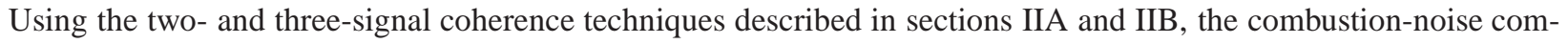
ponent $G_{w w}(f)$ of the far-field noise signature $G_{z z}(f)$, see Fig. 1 can be determined by

$$
G_{w w}(f)=\gamma_{\alpha z}^{2}(f) G_{z z}(f), \quad \alpha=x, y,
$$

where either the combustor sensor CIP1 $(\alpha=x)$ or the turbine-exit sensor T551 $(\alpha=y)$ is used in combination with the $130^{\circ}$ far-field microphone, and/or by

$$
G_{w w}(f)=\frac{\gamma_{x z}(f) \gamma_{y z}(f)}{\gamma_{x y}(f)} G_{z z}(f),
$$


where signals from CIP1 sensor, T551 sensor and the far-field microphone are utilized. These three choices will be referred to as the '2s-cip1', '2s-t551', and '3s' cases/methods in what follows. Equation (3a) is simply a restatement of Eq. (1) allowing for a choice in engine-internal signal and Eq. (3b) follows directly from Eq. (2c) by using the definition of coherence.

From a purely theoretical point of view, $0 \leqslant \gamma_{\alpha \beta} \leqslant 1$, with $\gamma_{\alpha \beta}=0$ meaning that the two signals $\alpha(t)$ and $\beta(t)$ are completely uncorrelated and $\gamma_{\alpha \beta}=1$ indicating perfectly correlated signals. In practice, only estimates $\hat{\gamma}_{\alpha \beta}$ of the coherence can be obtained using finite data series. The estimated coherence will, in fact, be nonzero even for completely uncorrelated signals, ${ }^{28,29}$ i.e., only the interval

$$
\epsilon<\hat{\gamma}_{\alpha \beta} \leqslant 1
$$

is meaningful, where

$$
\epsilon^{2}=1-\left(1-P_{I}\right)^{1 /\left(N_{s}-1\right)}
$$

is the $P_{I}$-percent confidence interval if the true $\gamma_{\alpha \beta}^{2}$ is zero and $N_{s}$ is the number of independent data segments used in obtaining $\hat{\gamma}_{\alpha \beta}^{2}$. Welch ${ }^{30}$ showed, in the context of estimating auto power spectra, that $N_{s}$ can be replaced by $9 M / 11$, where $M$ is the number of 50-percent-overlapped segments used in the analysis. Miles ${ }^{29}$ suggested that a better estimate for the coherence threshold value, or noise floor, $\epsilon$ can be obtained by purposely unaligning the two time series. That is, a time delay is deliberately introduced to ensure that the two resulting finite time series are uncorrelated. The estimated unaligned coherence does not depend on any particular assumptions about the underlying statistical properties of the time series and accounts for any data-segment overlap and algorithms used in the analysis. The unaligned result captures the coherence of any discrete tones present in the signals and also provides an estimate of the minimum observable broadband coherence. Miles ${ }^{29,31}$ found that Eq. [5] with $N_{s}=M$ provided a good estimate of the noise floor. Following Miles, ${ }^{29,31}$ the estimated coherence threshold for the present study is $\epsilon=0.0518$. If the estimated coherence exceeds the threshold the two time series are coupled. If it is less than the threshold the signals are random and appear independent for that particular number of samples/segments.

In the two-signal (coherent-output-power) method calculations carried out here, the estimated coherence $\hat{\gamma}_{\alpha z}(f)$ is replaced by the threshold value $\epsilon$ if it falls below that value for a particular narrow-band frequency. That is, the estimated narrow-band combustion-noise component $\hat{G}_{w w}(f)$ is simply set to $\epsilon^{2} \hat{G}_{z z}(f)$ for the frequency in question. Otherwise it is given by the equivalent of Eq. 3a. The narrow-band estimate is then frequency summed to yield the corresponding $1 / 3$-octave result for the far-field combustion-noise component.

Mathematically, it follows from Eq. (4) that

$$
\epsilon^{2}<\hat{\gamma}_{x z} \hat{\gamma}_{y z} / \hat{\gamma}_{x y}<\epsilon^{-1}
$$

The upper limit of this inequality is an unphysical result in view of Eq. $3 b$ and the fact that $\hat{G}_{w w}$ cannot be lager than $G_{z z}$. Clearly, an additional discriminator is needed to ensure a physically realistic three-signal combustion-noise estimate. This is provided by the following necessary condition for Eq. (2) to be valid:

$$
\Theta \equiv \arg \left[G_{x z} \operatorname{conj}\left(\mathrm{G}_{\mathrm{yz}}\right) / G_{x y}\right]=0 .
$$

The standard deviation (in radians) of the estimate for the cross-spectrum phase angle $\theta_{\alpha \beta}=\arg \left(G_{\alpha \beta}\right)$ is given by $y^{4,31}$

$$
\sigma_{\alpha \beta}=\sin ^{-1} \sqrt{\left(1-\gamma_{\alpha \beta}^{2}\right) / 2 \gamma_{\alpha \beta}^{2} N_{s}} .
$$

Note that the standard deviation is zero for perfectly correlated signals and increases as the coherence is diminished. Consequently, in the three-signal method calculations carried out here, the estimated narrow-band combustion-noise component for a particular narrow-band frequency $\hat{G}_{w w}(f)$ is set to $\epsilon^{2} \hat{G}_{z z}(f)$ if, any of the estimated coherence values, $\hat{\gamma}_{x z}, \hat{\gamma}_{y z}$, or $\hat{\gamma}_{x y}$, fall below the threshold value $\epsilon$, or if the estimated phase angle $\hat{\Theta}>\hat{\sigma}_{x z}+\hat{\sigma}_{y z}+\hat{\sigma}_{x y}$, where $\hat{\sigma}_{\alpha \beta}=\sin ^{-1} \sqrt{\left[1 / \max \left(\hat{\gamma}_{\alpha \beta}^{2}, \epsilon^{2}\right)-1\right] / 2 N_{s}}$. Otherwise it is given by the equivalent of Eq. $\left.3 b\right]$. The narrow-band estimate is then summed up to yield the corresponding $1 / 3$-octave result for the combustion-noise contribution to the far-field noise signature. Note that the discriminator procedure based on the phase angle is a new method.

\section{Statistical Uncertainty}

The textbook by Bendat \& Piersol ${ }^{4}$ gives a summary of statistical random error formulas for single input/output systems. From these, it follows that the statistical uncertainties for the present coherent-power-method estimates are 
given by

$$
\begin{gathered}
\mathcal{E}_{r}\left[\hat{G}_{z z}(f)\right]=\frac{1}{\sqrt{N_{s}}}, \\
\mathcal{E}_{r}\left[\hat{G}_{\alpha \beta}(f)\right]=\frac{1}{\gamma_{\alpha \beta} \sqrt{N_{s}}}, \\
\mathcal{E}_{r}\left[\hat{\gamma}_{\alpha \beta}^{2}(f)\right]=\frac{\sqrt{2}\left[1-\gamma_{\alpha \beta}^{2}(f)\right]}{\gamma_{\alpha \beta}(f) \sqrt{N_{s}}}, \\
\mathcal{E}_{r}\left[\hat{G}_{w w}(f)\right]=\frac{\left[2-\gamma_{\alpha z}^{2}(f)\right]^{1 / 2}}{\gamma_{\alpha z}(f) \sqrt{N_{s}}}, \quad \alpha=x, y,
\end{gathered}
$$

where $\mathcal{E}_{r}$ denotes the relative error/uncertainty. To evaluate these, the unknown true coherence $\gamma_{\alpha \beta}$ is replaced by its computed value $\hat{\gamma}_{\alpha \beta}$. Equation $9 a$ is the well known result that the uncertainty in an auto-spectrum estimation decreases as the inverse square root of the number averages used. This result shows that for the present computations, the statistical uncertainty of the total-noise auto spectrum is about 3.3 percent, which is an order of magnitude smaller than the 33 percent $(1.25 \mathrm{~dB})$ estimated measurement uncertainty. Equation $9 \mathrm{cc}$ shows that the uncertainty in the coherence vanishes as the signals become correlated. This indicates that computed coherence values are more accurate than the quantities used in its evaluation. It is also important to realize that the estimate $9 d$ also assumes that the input signal (see Fig. 11) does not contain a noise component, i.e., $m(t) \equiv 0$ when $\alpha(t)=x(t)$ or $n(t) \equiv 0$ for $\alpha(t)=y(t)$.

Using logarithmic differencing, it follows that the statistical uncertainty in the three-signal method can be expressed as

$$
\mathcal{E}_{r}\left[\hat{G}_{w w}(f)\right] \leqslant \frac{1}{2} \mathcal{E}_{r}\left[\hat{\gamma}_{x z}^{2}(f)\right]+\frac{1}{2} \mathcal{E}_{r}\left[\hat{\gamma}_{y z}^{2}(f)\right]+\frac{1}{2} \mathcal{E}_{r}\left[\hat{\gamma}_{x y}^{2}(f)\right]+\mathcal{E}_{r}\left[\hat{G}_{z z}(f)\right] .
$$

For perfectly correlated signals, both Eqs. $9 d$ and $(10)$ reduce to the equivalent of Eq. $9 a$. As the signals become uncorrelated, Eqs. (9d) and (10) indicate a relative uncertainty of $\sqrt{2 / \epsilon^{2} N_{s}}$ and $\frac{3}{2} \sqrt{2 / \epsilon^{2} N_{s}}$, respectively. Using the present number of data segments, the statistical uncertainty in the combustion-noise estimate is about 3 percent when the signals are highly correlated and becomes roughly 80 and 120 percent (depending on source-separation method) as they become poorly correlated. This suggests that the three-signal method is less robust than the two-signal methods when the coherence is small.

\section{Combustion-Noise 1/3-Octave Results}

The far-field signal $z(t)$ must be time shifted to account for the physical propagation delay between the engine-internal sensors and the $130^{\circ}$ microphone. Following Miles, ${ }^{31}$ the corresponding time series is shifted by 5800 points, which corresponds to an $88.5 \mathrm{~ms}$ time delay. Figure 3 shows the results of the source-separation procedures at the four engine power settings of 48,60,71, and 87 percent corrected fan speed (flight-idle, approach, cutback, and takeoff conditions) for the $1 / 3$-octave center frequency range of 20 to $1000 \mathrm{~Hz}$. The solid lines represent the ANOPP 1/3octave SPL predictions for the total (dark-grey) and combustion (red-brown) noise. The symbols correspond to results computed from the experimental time histories as described above. The black squares, labeled $G_{z z}$, represent the total noise signature, which is reasonably well predicted by the ANOPP results. The grey squares, labeled NOP, correspond to the threshold value for the coherent output power and any combustion-noise result below these values would not be meaningful using the present number of data segments and source-separation techniques. The blue, red, and green squares correspond to the combustion noise detected using the three methods '2s-cip1', '2s-t551', and ' $3 \mathrm{~s}$ ', respectively.

By comparing the results for the three different cases, the effect of the positive-bias error inherent in the two-signal method, not unexpectedly, leads to an underprediction of the peak value when the combustor-internal sensor CIP1 is used. The two-signal method utilizing the turbine-exit sensor T551 and the three-signal method both clearly detect a single combustion noise peak, but indicate that the $400 \mathrm{~Hz}$ combustion-peak location used in ANOPP is not adequate for this particular engine. The peak occurs at least two 1/3-octave bands lower. The ANOPP peak value also appears to be at least $3 \mathrm{~dB}$ too low.

Harper-Bourne et al., ${ }^{32}$ in their combustor-noise study of the large ANTLE research engine, have suggested that the difference between the two-signal results using combustor-internal and exit-pipe sensors, respectively, can be explained on the basis of the presence of both direct and indirect combustion noise. They argue that the first method educes only direct combustion noise, whereas the second one detects the total (direct + indirect) combustion noise. Their argument is incorrect, however. First, the inherent bias error in the coherent-output-power method can without 
doubt be expected to be much larger when a combustor internal sensor is utilized compared to when a core tail-pipe sensor is used. This, by itself, is sufficient to explain the difference in the results. Second, Miles ${ }^{31,33}$ has carried out a coherence analysis with adjustable time delay in order to maximize the coherence and minimize the phase-angle variation with frequency using the same engine data as the present study. $\mathrm{He}$ observed that the signal in the $0-200 \mathrm{~Hz}$ frequency band took longer time than the signal in the $200-400 \mathrm{~Hz}$ range to travel to the far-field microphone. He concluded that the coherent signal in the $0-200 \mathrm{~Hz}$ frequency band is partially due to indirect combustion noise and that in the $200-400 \mathrm{~Hz}$ band it is due mostly to direct combustion noise. This is the opposite situation to that of the argument in Ref. 32, where it is assumed that direct noise is dominant for frequencies less than $100 \mathrm{~Hz}$ and entropy (indirect) noise peaks at $200 \mathrm{~Hz}$ and is dominant at higher frequencies.

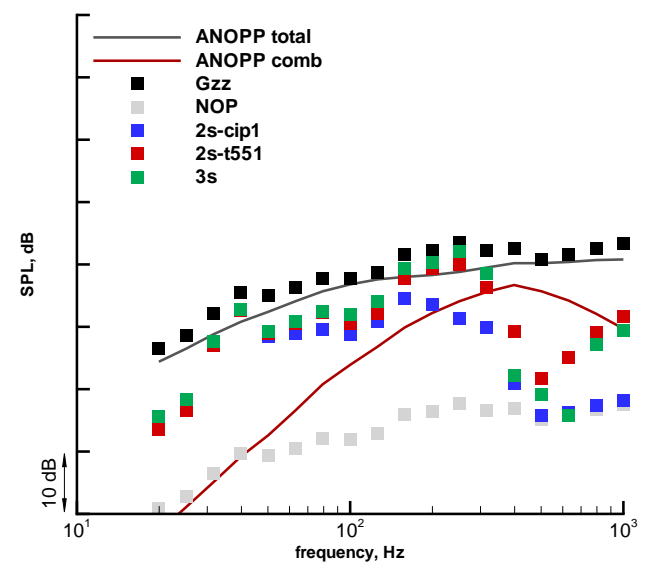

(a)

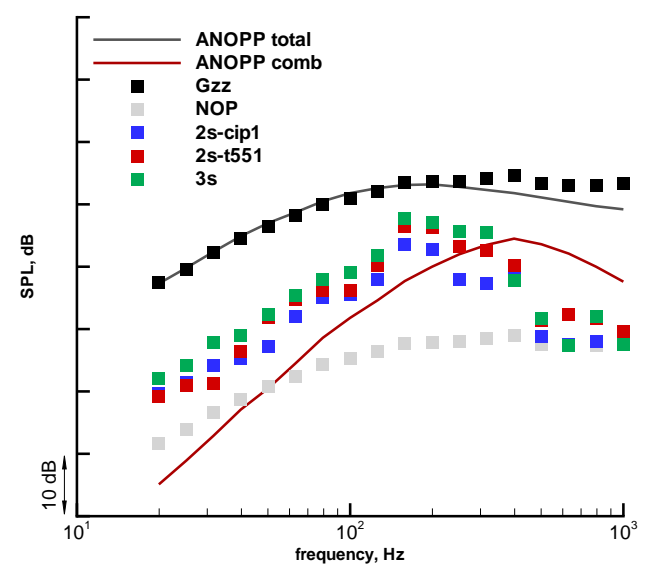

(c)

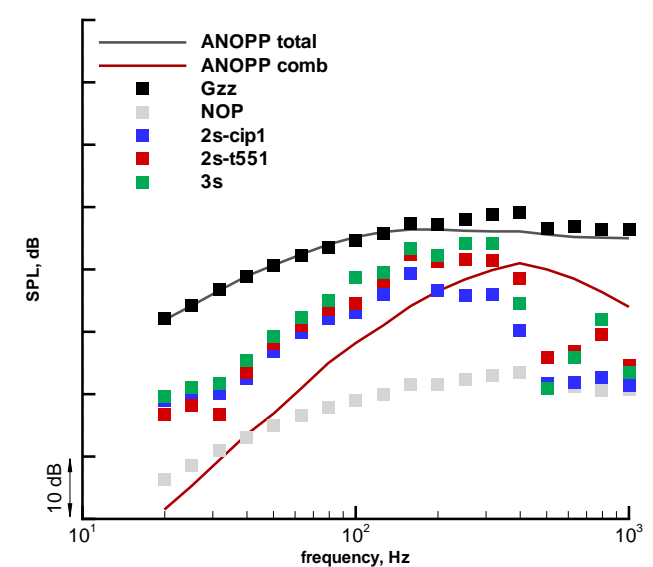

(b)

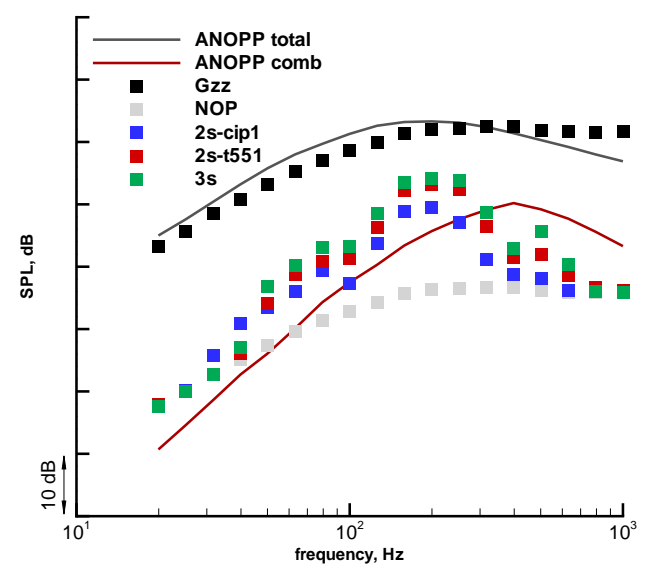

(d)

Figure 3. Total and combustion-noise 1/3-octave SPL versus 1/3-octave center frequency in the $130^{\circ}$ direction; (a): $48 \%$ corrected fan speed (flight idle); (b): $60 \%$ corrected fan speed (approach); (c): $71 \%$ corrected fan speed (cutback); (d): $87 \%$ corrected fan speed (takeoff)

\section{E. Combustion-Noise Narrow-Band Results}

Figure 4 shows the far-field narrow-band results of the source separation procedures for the flight-idle condition of 48 percent corrected fan speed in the $130^{\circ}$ direction. Panels (a) - (c) show the total- and combustion-noise narrow-band ( $8 \mathrm{~Hz}$ ) SPL for the '2s-cip1', '2s-t551', and '3s' methods, respectively. The black and grey curves show the total noise signature $G_{z z}$ and the threshold value $\epsilon^{2} G_{z z}$ for the coherent output power. The blue, red, and green curves in these panels represent the corrected engine-internal-coherent noise for the three source-separation techniques, whereas the cyan, magenta, and orange curves show the corresponding raw results. Panel (d) shows the three-signal method phase angle, Eq. 7. The green, orange, and black curves denote the corrected phase angle, raw phase angle, and limits, 


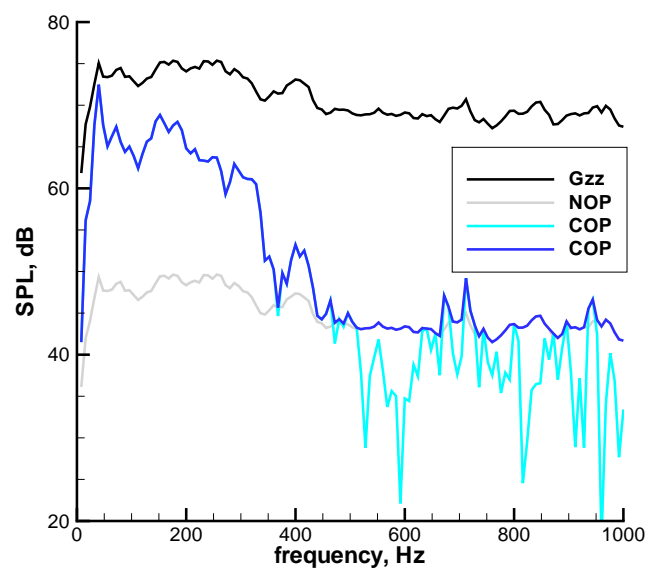

(a)

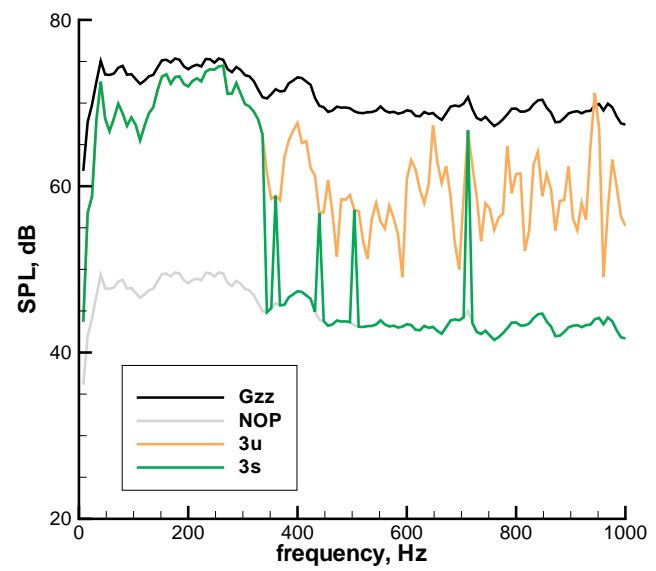

(c)

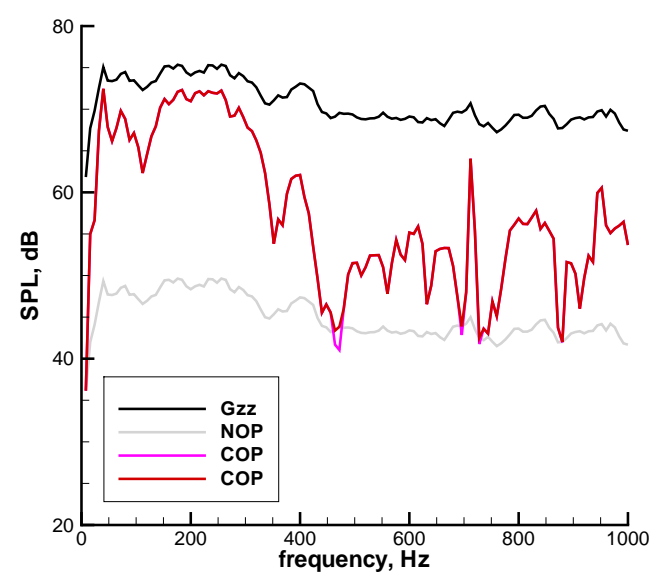

(b)

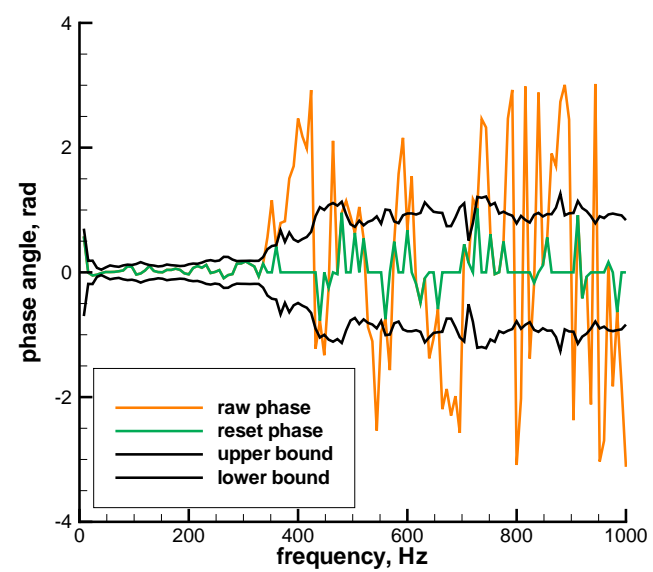

(d)

Figure 4. Narrow-band $(8 \mathrm{~Hz})$ far-field results in the $130^{\circ}$ direction at $48 \%$ corrected fan speed (flight idle). (a) - (c): total and combustionnoise narrow-band SPL versus frequency; black curves-total noise signature; gray curves-noise floor; blue and cyan curves-corrected and uncorrected combustion noise using combustor sensor and far-field microphone; red and magenta curves-corrected and uncorrected combustion noise using turbine-exit sensor and far-field microphone; green and orange curves-corrected and uncorrected combustion noise using combustor and turbine-exit sensors and far-field microphone. (d): three-signal method phase; black curves-limits; green and orange curves-reset and raw phase.

respectively. Whenever the raw angle exceeds the limits, the computed raw estimate of the coherent noise is rejected and replaced by the corresponding noise-limit value [gray curve in Panel (c)]. To simplify the comparison of the methods, the corrected engine-internal coherent results are replotted in Figure 5 a). The black and gray curves denote the total noise signature and the noise floor of the methods. The blue, red, and green curves show the coherent noise estimated by the '2s-cip1', '2s-t551', and '3s' methods, respectively. The figure shows that broadband combustion noise is identified below about $350 \mathrm{~Hz}$ by all three methods. It can also be seen that bias error in the '2s-cip1' method, as can be expected, leads to an underprediction of the peak value. The results from the ' $2 \mathrm{~s}-\mathrm{t} 551$ ' and ' $3 \mathrm{~s}$ ' methods are in good agreement in this frequency range, however. Broadband noise in the $350-450 \mathrm{~Hz}$ range is only detected by the two-signal methods. The reason that the three-signal method fails to detect broadband noise is likely due to the lower levels of coherence in this latter frequency range. The three-signal method becomes less robust as the coherence decreases. The red curve in this figure shows that the '2s-t551' method also indicates the presence of coherent broadband noise for frequencies larger than about $450 \mathrm{~Hz}$. Even though the exact source of this noise is not clear, it is definitely associated with the turbine.

Figure 5 b) shows the corresponding deliberately unaligned results. The color legend is the same as in Fig. [5 a). The far-field microphone time series is here shifted by 16500 points, which corresponds to a $251.8 \mathrm{~ms}$ time delay, to purposely decorrelate any broadband component present in the signals. All three methods detect what is believed to 
be an $\mathrm{N} 2$ compressor-disk tone at about $350 \mathrm{~Hz}$. The origin of the hump below about $50 \mathrm{~Hz}$ is not clear. The nature of the discrete peak, in both panels, at about $700 \mathrm{~Hz}$ is also not obvious.

Figure 6 shows the far-field narrow-band results of the three methods for the approach condition of 60 percent corrected fan speed in the $130^{\circ}$ direction. Panels (a) - (c) show the total- and combustion-noise narrow-band (8 Hz) SPL for the '2s-cip1', '2s-t551', and '3s' methods, respectively. The black and grey curves again show the total noise signature and the threshold value for the coherent output power. The blue, red, and green curves in these panels represent the corrected coherent noise for the three source-separation techniques, whereas the cyan, magenta, and orange curves show the corresponding unaligned results. The figure indicates the presence of broadband combustion noise in a frequency range up to about $400 \mathrm{~Hz}$. The ' $2 \mathrm{~s}$-cip1' method also here underpredicts the peak value due to the positive-bias error inherent in the coherent-output method. The estimated combustion noise using the ' $2 \mathrm{~s}$-t551' and ' $3 \mathrm{~s}$ ' methods generally agree also here, except that a more rapid right-side fall-off of the broadband peak is predicted by the latter method.

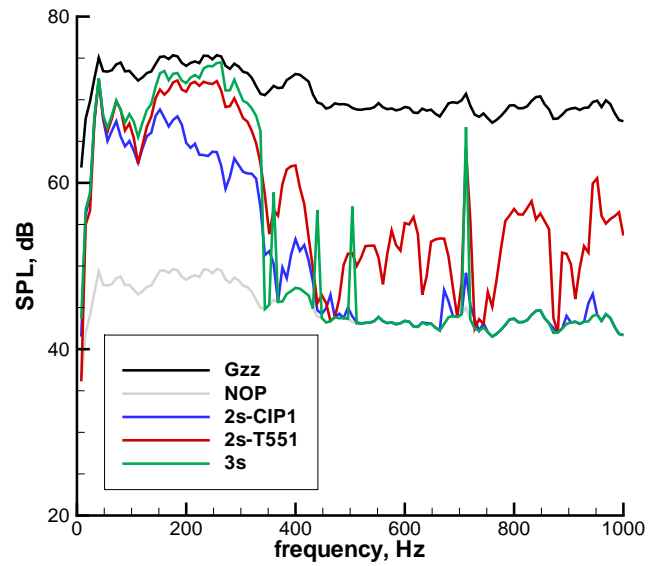

(a)

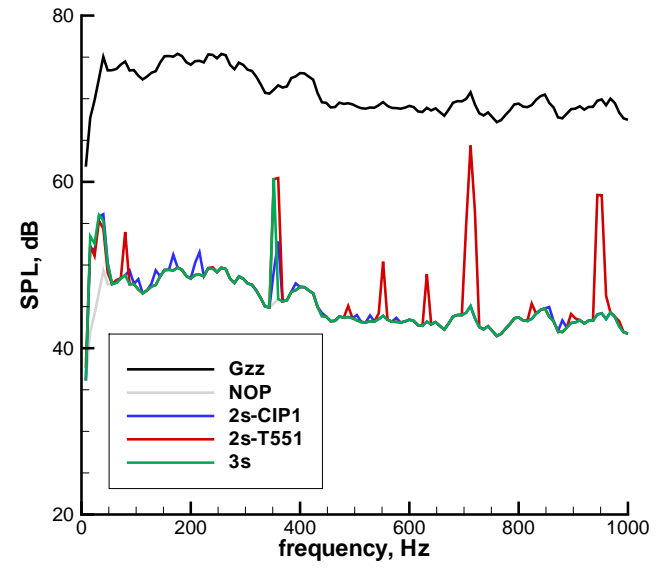

(b)

Figure 5. Aligned (a) and unaligned (b) narrow-band $(8 \mathrm{~Hz})$ far-field SPL versus frequency in the $130^{\circ}$ direction at $48 \%$ corrected fan speed (flight idle); black and grey curves—-total noise signature and noise floor; blue. red, and green curves—corrected engine-internal coherent noise using combustor sensor, turbine-exit sensor, and combustor and turbine-exit sensors all in combination with the far-field $130^{\circ}$ microphone

The results in Fig. 6 are in general agreement with the ones presented by Mendoza et al. ${ }^{25}$ in their Fig. 12(b). For the two coherent-output (two-signal) methods, there is good agreement between the present results and theirs for both the frequency range and levels of the estimated broadband combustion noise. There are some differences for the three-signal method results, however. The present ones are obtained using one combustor sensor, a turbine-exit sensor and the $130^{\circ}$ far-field microphone. Their results were obtained using three far-field microphones $\left(110^{\circ}, 130^{\circ}\right.$, and $160^{\circ}$ ). There are significant differences for frequencies less than about $50 \mathrm{~Hz}$ and larger than, say, $350 \mathrm{~Hz}$, with their results suggesting the presence coherent noise, in contradiction to our results (all three methods) and their own coherent-output results. There is reasonable agreement, however, for frequencies in the $50-350 \mathrm{~Hz}$ range between their three-signal result and the present one.

\section{Summary}

Within the limitations of static-engine measurements, the ANOPP total-noise predictions agree well with the EVNERT data, considering their semi-empirical base. The source-separation methods applied here to the EVNERT data show that the ANOPP combustion-noise predictions are not adequate for the particular engine used in the test. To enable future 'quiet' aircraft engines, progress must be made in the understanding and modeling of the now subdominant combustion noise and its turbine transmission/interaction.

A new and additional discriminator for the three-signal method, based on its phase angle and a statistical condition, is also described and successfully applied herein. 


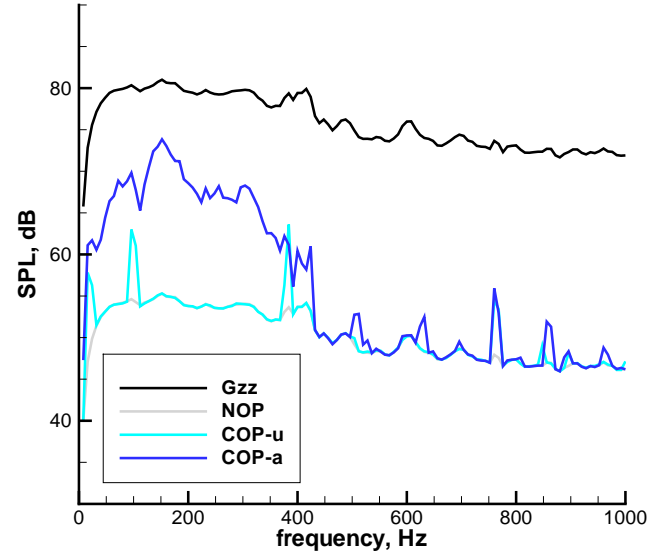

(a)

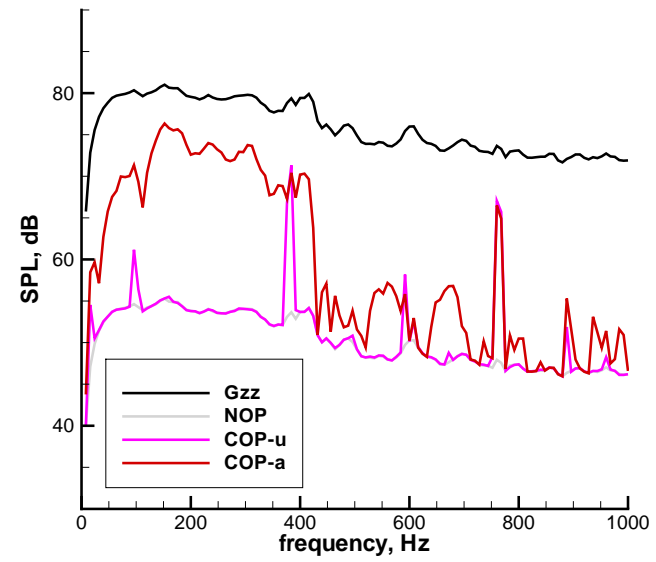

(b)

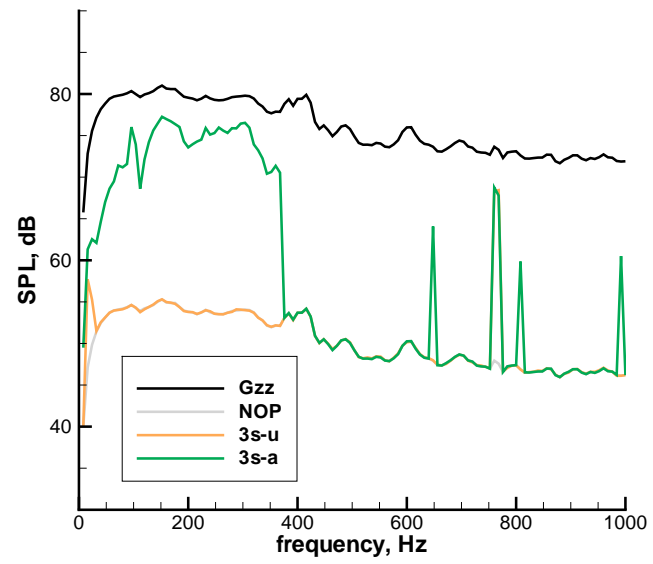

(c)

Figure 6. Far-field narrow-band $(8 \mathrm{~Hz})$ total and combustion-noise SPL versus frequency in the $130^{\circ}$ direction at $60 \%$ corrected fan speed (approach); black and gray curves-total noise signature and noise floor. (a): two-signal method using combustor sensor and far-field microphone; blue and cyan curves-aligned- and unaligned-case coherent noise. (b): two-signal method using turbine-exit sensor and farfield microphone; red and magenta curves-aligned- and unaligned-case coherent noise. (c): three-signal method using using combustor and turbine-exit sensors and far-field microphone; green and orange curves—aligned- and unaligned-case coherent noise

\section{References}

${ }^{1}$ J. F. Groeneweg, T. G. Sofrin, E. J. Rice, and P. R. Gliebe. Turbomachinery noise. In H. H. Hubbard, editor, Aeroacoustics of Fligh Vehicles: Theory and Practice, volume 1, chapter 3, pages 151-209. NASA Reference Publication 1258, WRDC Technical Report 90-3052, 1991.

${ }^{2}$ R. J. Mahan and A. Karchmer. Combustion and core noise. In H. H. Hubbard, editor, Aeroacoustics of Fligh Vehicles: Theory and Practice, volume 1, chapter 9, pages 483-517. NASA Reference Publication 1258, WRDC Technical Report 90-3052, 1991.

${ }^{3}$ H. H. Hubbard, editor. Aeroacoustics of Fligh Vehicles: Theory and Practice, Volume 1 and 2. NASA Reference Publication 1258, WRDC Technical Report 90-3052, 1991.

${ }^{4}$ J. S. Bendat and A. G. Piersol. Engineering Applications of Correlation and Spectral Analysis. Wiley-Interscience, 1980.

${ }^{5}$ A.M. Karchmer and M. Reshotko. Core noise source diagnostics on a turbofan engine using correlation and coherence techniques. Technical Report NASA TM-X-73535, NASA, 1976. 
${ }^{6}$ M. Reshotko, A. M. Karchmer, P. F. Penko, and J. G. McArdle. Core noise measurements on a YF-102 turbofan engine. J. Aircraft, vol. 14, no. 7, pp. 611-612, 1977.

${ }^{7}$ A. M. Karchmer. Identification and measurement of combustion noise from a turbofan engine using correlation and coherence techniques. Technical Report NASA TM-73747, NASA, 1977.

${ }^{8}$ A. M. Karchmer, M. Reshotko, and F. J. Montegani. Measurement of far-field combustion noise from a turbofan engine using coherence functions. Technical Report AIAA Paper 1977-1277 (NASA TM-73748), 4th AIAA Aeroacoustics Conference, Atlanta, Georgia, 1977.

${ }^{9}$ M. Reshotko and A. M. Karchmer. Core noise measurements from a small, general aviation turbofan engine. Technical Report NASA TM-81610, NASA, 1980.

${ }^{10}$ V. L. Doyle and M. T. Moore. Core noise investigation of the CF6-50 turbofan engine. Technical Report NASA CR-159749, NASA, 1980.

${ }^{11}$ E. A. Krejsa. New technique for the direct measurement of core noise from aircraft engines. Technical Report AIAA Paper 1981-1587 (NASA TM-82634), 17th AIAA/SAE/ASME Joint Propulsion Conference, Colorado Springs, Colorado, 1981.

${ }^{12}$ E. A. Krejsa. Application of 3-signal coherence to core noise transmission. Technical Report AIAA Paper 1983-0759 (NASA TM-83333), 8th AIAA Aeroacoustics Conference, Atlanta, Georgia, 1983.

${ }^{13}$ E. A. Krejsa. Combustion noise from gas turbine aircraft engines measurement of far-field levels. Technical Report NASA TM-88971, NASA, 1987.

${ }^{14}$ A. M. Karchmer. Acoustic modal analysis of a full scale annular combustor. Technical Report AIAA Paper 1983-0760 (NASA TM-83334), 8th AIAA Aeroacoustics Conference, Atlanta, Georgia, 1983.

${ }^{15}$ J. H. Miles and E. A. Krejsa. Pressure transfer function of a JT15D nozzle due to acoustic and convected entropy fluctuations. J. Acoustical Society of America, vol. 72, no. 6, pp. 2008-2019, 1982.

${ }^{16}$ E. A. Krejsa and A. M. Karchmer. Acoustic modal analysis of the pressure field in the tailpipe of a turbofan engine. Technical Report NASA TM-83387, NASA, 1983.

${ }^{17}$ J. H. Miles, C. A. Wasserbauer, and E. A. Krejsa. Cross spectra between temperature and pressure in a constant area duct downstream of a combustor. Technical Report AIAA Paper 1983-0762 (NASA TM-83351), 8th AIAA Aeroacoustics Conference, Atlanta, Georgia, 1983.

${ }^{18}$ J. Y. Chung. Rejection of flow noise using a coherence function method. J. Acoustical Society of America, vol. 62, no. 2, pp. 388-395, 1977.

${ }^{19}$ S. P. Parthasarathy, R. F. Cuffel, and P. F. Massier. Separation of core noise and jet noise. AIAA J., vol. 18, no. 3, pp. 256-261, 1980.

${ }^{20}$ B. J. Tester and M. J. Fisher. Engine noise source breakdown: Theory, simulation and results. Technical Report AIAA Paper 1981-2040, 7th AIAA Aeroacoustics Conference, Palo Alto, California, 1981.

${ }^{21}$ B. N. Shivashankara. High bypass ratio engine noise component separation by coherence technique. J. Aircraft, vol. 20, no. 3, pp. 236-242, 1983.

${ }^{22}$ U. von Glahn and E. A. Krejsa. Correlation of core noise obtained by three-signal coherence techniques. Technical Report NASA TM-83012, NASA, 1982.

${ }^{23}$ W. E. Zorumski. Aircraft noise prediction program theoretical manual, part 1. Technical Report NASA TM-83199-Pt-1, NASA, 1982.

${ }^{24}$ W. E. Zorumski. Aircraft noise prediction program theoretical manual, part 2. Technical Report NASA TM-83199-Pt-2, NASA, 1982.

${ }^{25}$ J. M. Mendoza, D. K. Nance, and K. K. Ahuja. Source separation from multiple microphone measurements in the far field of a full scale aero engine. Technical Report AIAA Paper 2008-2809, 14th AIAA/CEAS Aeroacoustic Conference, Vancouver, British Columbia, 2008.

${ }^{26}$ D. S. Weir, editor. Engine validation of noise and emission reduction technology phase I. Technical Report NASA CR-2008-215225, NASA, 2008. Honeywell Report No. 21-13843, Honeywell Aerospace, Phoenix, Arizona.

${ }^{27}$ J. S. Hsu and K. K. Ahuja. A coherence-based technique to separate internal mixing noise from farfield measurements. Technical Report AIAA Paper 1998-2296, 4th AIAA/CEAS Aeroacoustic Conference, Toulouse, France, 1998.

${ }^{28}$ D. R. Brillinger. Time Series Data Analysis and Theory. Holden-Day, 1981.

${ }^{29}$ J. H. Miles. Aligned and unaligned coherence: A new diagnostic tool. Technical Report AIAA Paper 2006-0010 (NASA TM-2006-214112), 44th Aerospace Sciences Meeting, Reno, Nevada, 2006.

${ }^{30} \mathrm{P}$. D. Welch. The use of fast fourier transform for the estimation of power spectra: A method based on time averaging over short, modified periodograms. IEEE Transactions on Audio and Electroacoustics, vol. AU-15, no. 2, pp. 70-73, 1967.

${ }^{31}$ J. H. Miles. Spectral separation of the turbofan engine coherent combustion noise component. Technical Report AIAA Paper 2008-0050 (NASA TM-2008-215157), 46th Aerospace Sciences Meeting, Reno, Nevada, 2008.

${ }^{32}$ M. Harper-Bourne, A. Moore, and H. Siller. A study of large aero-engine combustor noise. Technical Report AIAA Paper 2008-2942, 14th AIAA/CEAS Aeroacoustic Conference, Vancouver, British Columbia, 2008.

33 J. H. Miles. Time delay analysis of turbofan engine direct and indirect combustion noise sources. J. Propulsion and Power, vol. 25, no. 1, pp. 218-227, 2009. 


\begin{tabular}{|c|c|c|c|c|c|}
\hline \multicolumn{5}{|c|}{ REPORT DOCUMENTATION PAGE } & $\begin{array}{l}\text { Form Approved } \\
\text { OMB No. 0704-0188 }\end{array}$ \\
\hline \multicolumn{6}{|c|}{$\begin{array}{l}\text { The public reporting burden for this collection of information is estimated to average } 1 \text { hour per response, including the time for reviewing instructions, searching existing data sources, gathering and maintaining the } \\
\text { data needed, and completing and reviewing the collection of information. Send comments regarding this burden estimate or any other aspect of this collection of information, including suggestions for reducing this } \\
\text { burden, to Department of Defense, Washington Headquarters Services, Directorate for Information Operations and Reports (070704-0188, } 1215 \text { Jefferson Davis Highway, Suite } 1204 \text {, Arlington, VA } 22202-4302 \text {. } \\
\text { Respondents should be aware that notwithstanding any other provision of law, no person shall be subject to any penalty for failing to comply with a collection of information if it does not display a currently valid OME } \\
\text { control number. } \\
\text { PLEASE DO NOT RETURN YOUR FORM TO THE ABOVE ADDRESS. }\end{array}$} \\
\hline \multicolumn{2}{|c|}{$\begin{array}{l}\text { 1. REPORT DATE (DD-MM-YYYY) } \\
01-11-2009\end{array}$} & \multicolumn{3}{|c|}{$\begin{array}{l}\text { 2. REPORT TYPE } \\
\text { Technical Memorandum }\end{array}$} & 3. DATES COVERED (From - To) \\
\hline \multirow{3}{*}{\multicolumn{5}{|c|}{$\begin{array}{l}\text { 4. TITLE AND SUBTITLE } \\
\text { Noise-Source Separation Using Internal and Far-Field Sensors for a Full-Scale Turbofan } \\
\text { Engine }\end{array}$}} & 5a. CONTRACT NUMBER \\
\hline & & & & & 5b. GRANT NUMBER \\
\hline & & & & & 5c. PROGRAM ELEMENT NUMBER \\
\hline \multirow{3}{*}{\multicolumn{5}{|c|}{$\begin{array}{l}\text { 6. AUTHOR(S) } \\
\text { Hultgren, Lennart, S.; Miles, Jeffrey, H. }\end{array}$}} & 5d. PROJECT NUMBER \\
\hline & & & & & 5e. TASK NUMBER \\
\hline & & & & & $\begin{array}{l}\text { 5f. WORK UNIT NUMBER } \\
\text { WBS 561581.02.08.03.18.02 }\end{array}$ \\
\hline \multicolumn{5}{|c|}{$\begin{array}{l}\text { 7. PERFORMING ORGANIZATION NAME(S) AND ADDRESS(ES) } \\
\text { National Aeronautics and Space Administration } \\
\text { John H. Glenn Research Center at Lewis Field } \\
\text { Cleveland, Ohio 44135-3191 }\end{array}$} & $\begin{array}{l}\text { 8. PERFORMING ORGANIZATION } \\
\text { REPORT NUMBER } \\
\text { E-17096 }\end{array}$ \\
\hline \multirow{2}{*}{\multicolumn{5}{|c|}{$\begin{array}{l}\text { 9. SPONSORING/MONITORING AGENCY NAME(S) AND ADDRESS(ES) } \\
\text { National Aeronautics and Space Administration } \\
\text { Washington, DC 20546-0001 }\end{array}$}} & $\begin{array}{l}\text { 10. SPONSORING/MONITOR'S } \\
\text { ACRONYM(S) } \\
\text { NASA; AIAA }\end{array}$ \\
\hline & & & & & $\begin{array}{l}\text { 11. SPONSORING/MONITORING } \\
\text { REPORT NUMBER } \\
\text { NASA/TM-2009-215834; AIAA-2009- } \\
3220\end{array}$ \\
\hline \multicolumn{6}{|c|}{$\begin{array}{l}\text { 12. DISTRIBUTION/AVAILABILITY STATEMENT } \\
\text { Unclassified-Unlimited } \\
\text { Subject Category: } 71 \\
\text { Available electronically at http://gltrs.grc.nasa.gov } \\
\text { This publication is available from the NASA Center for AeroSpace Information, 443-757-5802 }\end{array}$} \\
\hline \multicolumn{6}{|c|}{ 13. SUPPLEMENTARY NOTES } \\
\hline \multicolumn{6}{|c|}{$\begin{array}{l}\text { 14. ABSTRACT } \\
\text { Noise-source separation techniques for the extraction of the sub-dominant combustion noise from the total noise signatures obtained in } \\
\text { static-engine tests are described. Three methods are applied to data from a static, full-scale engine test. Both } 1 / 3 \text {-octave and narrow-band } \\
\text { results are discussed. The results are used to assess the combustion-noise prediction capability of the Aircraft Noise Prediction Program } \\
\text { (ANOPP). A new additional phase-angle-based discriminator for the three-signal method is also introduced. }\end{array}$} \\
\hline \multicolumn{6}{|c|}{$\begin{array}{l}\text { 15. SUBJECT TERMS } \\
\text { Turbomachinery core noise; Combustion noise; Noise-source separation }\end{array}$} \\
\hline \multicolumn{3}{|c|}{ 16. SECURITY CLASSIFICATION OF: } & $\begin{array}{l}\text { 17. LIMITATION OF } \\
\text { ABSTRACT }\end{array}$ & $\begin{array}{l}\text { 18. NUMBER } \\
\text { OF }\end{array}$ & $\begin{array}{l}\text { 19a. NAME OF RESPONSIBLE PERSON } \\
\text { STI Help Desk (email:help@sti.nasa.gov) }\end{array}$ \\
\hline $\begin{array}{l}\text { a. REPORT } \\
\text { U }\end{array}$ & $\begin{array}{l}\text { b. ABSTRACT } \\
\text { U }\end{array}$ & \begin{tabular}{|l|} 
c. THIS \\
PAGE \\
U \\
\end{tabular} & UU & $\begin{array}{l}\text { PAGES } \\
17\end{array}$ & $\begin{array}{l}\text { 19b. TELEPHONE NUMBER (include area code) } \\
443-757-5802\end{array}$ \\
\hline
\end{tabular}



